\title{
Poly (N-Methyl Aniline)-Li Nanocomposite as an Electrolyte for Rechargeable Battery: In-situ Recipe
}

\author{
Nishigandh Pande ${ }^{* 1}$, Adinath Jambhale ${ }^{1}$, Dipika Jaspal ${ }^{2}$, Jalinder Ambekar $^{3}$, Himanshu Patil ${ }^{1}$ \\ ${ }^{1}$ School of Mechatronics Engineering, Symbiosis Skills and Professional University, Village - Kiwale, Adjoining Pune Mumbai \\ Expressway, Pune - 412101, Maharashtra, India. \\ ${ }^{2}$ Symbiosis Institute of Technology (SIT), Symbiosis International (Deemed University)(SIU), Gram: Lavale, Tal: Mulshi, Pune- \\ 412115, Maharashtra, India \\ ${ }^{3}$ Centre for Materials for Electronics Technology (C-MET) Panchawati Road, Pashan, Pune- 411008, Maharashtra, India.
}

\begin{abstract}
The synthesis of cost-effective and safe polymeric nanocomposite materials has been a subject of interest and study for material science researchers. Poly (N-Methyl Aniline) - Li nanocomposite has been synthesized by a one-pot in-situ method and has been explored as an electrolyte in the battery. Poly (N-Methyl Aniline)-Li nanocomposite prepared, has been characterized by UV-visible, FTIR, FE-SEM, X-ray diffraction techniques. A mechanism of interaction of lithiumion with nitrogen at the imine site has been proposed. The charge-discharge process of poly (N-Methyl Aniline) - Li nanocomposite, when used in the battery, has been discussed.
\end{abstract}

Keywords: PNMA-Li nanocomposite, morphology, FESEM, battery

\section{Introduction}

Long term performance and rechargeable ability play a vital role in lithium-ion battery technology. Nowadays, the $\mathrm{Li}^{+}$ion battery is a crucial component of the automotive industry [1]. Organic-inorganic composite layers have been developed to obtain a contemporary electrolytic material with enhanced properties $[2,3]$. For the past few years, researchers are trying to revise the intercalation of conducting polymeric material by adding inorganic nanoscale materials as hosts. Substituted polyaniline has been chosen as a conducting polymeric material in the present research paper due to its optical and electrical properties [4-6].

The present article reports a facile synthesis method for developing poly( N-methyl aniline)-Li(PNMA-Li) nanocomposite as an electrolyte for battery, prepared by the in-situ green route technique, using the extract of Plumeriarubra flowers. ${ }^{1}$

\footnotetext{
*Corresponding author: nishigandh.pande@gmail.com
}

\section{Experimental Section}

\subsection{Materials and methods}

Lithium ions were prepared in the nano form using Plumeriarubra flowers, after which the preparation of the poly( N-methyl aniline)-Li nanocomposite was carried out.

The extract of Plumeriarubra flowers were used to prepared lithium ion nanoparticles by thoroughly washing the petals with deionized water and extracting using soxhlet apparatus.

\subsection{Synthesis of Lithium nanoparticles}

$20 \mathrm{~mL}$ of extract was used to synthesize nano lithium ions. The extract, along with $10 \mathrm{~mL}$ of $10 \% \mathrm{DL}$ tartaric acid, was blended with $0.025 \mathrm{M} \mathrm{LiNO}_{3}$ in presence of ultrasonic waves at $28^{\circ} \mathrm{C}$ for a half-hour, to give fain pink colour of lithium nanoscalematerial [7].

\subsection{Synthesis of Poly (N-methyl aniline)-Li nanocomposite \\ $10 \mathrm{~mL}$ of $\mathrm{Li}+$ ion nanomaterial was taken in $200 \mathrm{~mL}$ of a round bottom flask. N-methyl aniline (monomer) was dissolved in DL tartaric acid (acting as doping agent), and added to the container containing lithium nano ions with constant stirring. Ammonium}


persulphate was added as an oxidizing reagent in the resultant mixture at 0 to $5{ }^{\circ} \mathrm{C}$ with continuous agitation. After 20 minutes of mixing the reaction mixture showed a dark emerald color indicative of the Poly (N-methyl aniline)-Li nanocomposite formed as the final yield.

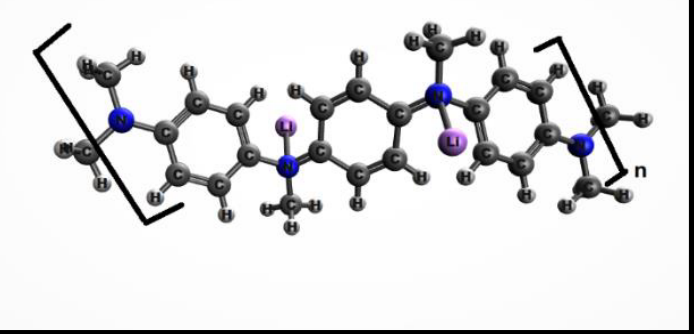

Fig.1.Structure of Poly (N- methyl aniline)-Li Nanocomposite

\section{Characterization}

The nanocomposite material synthesized was characterized by UV-visible spectroscopy. The absorption spectra were observed in the range of 200 to $800 \mathrm{~nm}$ wavelength. The nanocomposite was analyzed by X-ray diffraction with monochromatized $\mathrm{Cu} \mathrm{Ka}(\lambda 1.5418 \AA)$. The size distribution and morphology of nanocomposite were obtained by FESEM using JEOL-JSM-S4800. FTIR (Fourier transform infrared) spectral studies were carried out using Nicolet 67 FTIR spectrometer with $\mathrm{KBr}$ pellets used for analysis.

\section{Result and Discussion}

\subsection{UV-Visible Spectroscopy}

The nanocomposite showed absorption peaks at 265 , 370,450 , and $800 \mathrm{~nm}$. The absorption band of acidic range was observed at $265 \mathrm{~nm}$. These absorption band at $370 \mathrm{~nm}$ emanated from $\pi-\pi^{*}$ electron transition for the benzenoid present in synthesized nanocomposite. The absorption peak at 450 showed formation of $\mathrm{N}=\mathrm{Q}=\mathrm{N}$ (salt formed due to doping) in nanocomposite. The absorption spectra moving towards higher level $(800 \mathrm{~nm})$ indicating the emeraldine state of nanocomposite [8].

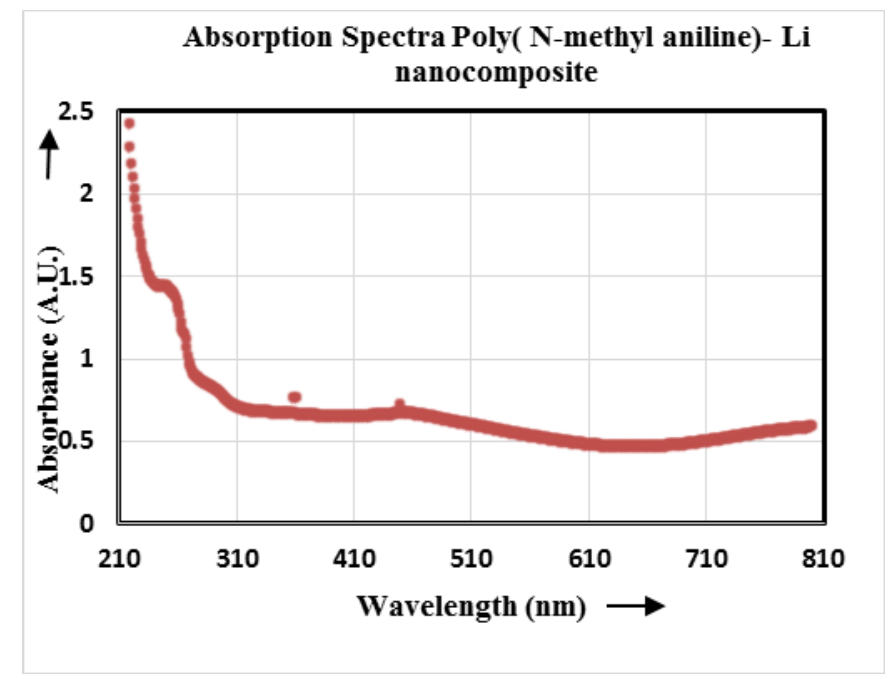

Fig.2.Poly (N- methyl aniline)-Li nanocomposite : UVvisible spectra

\subsection{FTIR}

The FTIR spectrum of Poly (N-methyl aniline)/Li nanocomposite has been portrayed in Figure 2. The spectrum shows a vibration band at $\sim 3600-3000 \mathrm{~cm}^{-1}$ for $-\mathrm{N}-\mathrm{H}$ stretching and $3000-2800 \mathrm{~cm}^{-1}$ for $\mathrm{C}-\mathrm{H}$ stretching, due to Poly (N-methyl aniline). Prominent peaks obtained at $1524 \mathrm{~cm}^{-1}$ and $1659 \mathrm{~cm}^{-1}$ were related to stretching vibrations due to $\mathrm{C}=\mathrm{N}$ of the quinoid and benzenoid ring the $\mathrm{C}=\mathrm{C}$ stretching, in the poly (N-methyl aniline)/Li nanocomposite. A stretching vibration at $1511 \mathrm{~cm}^{-1}$ was observed for the aromatic ring in Poly (N-methyl aniline)/Li nanocomposite. Signals at 1264 and $1131 \mathrm{~cm}^{-1}$ resulted from $\mathrm{C}-\mathrm{N}$ stretching $[4,5]$. The vibration at $551 \mathrm{~cm}^{-1}$ was attributed to the linear Lithium [9].

\subsection{X-ray Diffraction}

Figure 3 shows a broad peak at $2 \theta=22.03^{\circ}$, indicating a semi-crystalline polymeric material in the Poly (Nmethyl aniline)/Li nanocomposite. Remaining peaks for Lithium were observed at $2 \theta=18.96,30.46$, $35.44,36.26,40.72,43.66$, and 47.86, which were broad peaks indicative of the size of Lithium particles in nano sizes. The particle sizes of Lithium nanoparticles, as calculated using Debye Scherrer's equation (Eqn. 1), were $\sim 50 \mathrm{~nm}[10]$.

$D=\frac{0.9 \lambda}{\beta \cdot \operatorname{Cos} \theta}$ 


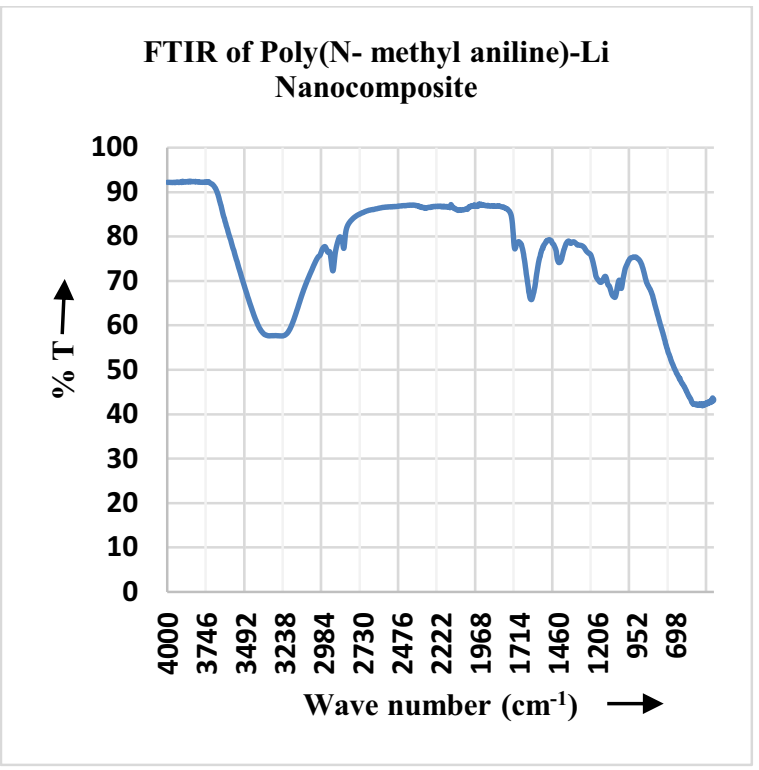

Fig.3. Poly (N- methyl aniline)-Li nanocomposite: FTIR spectra

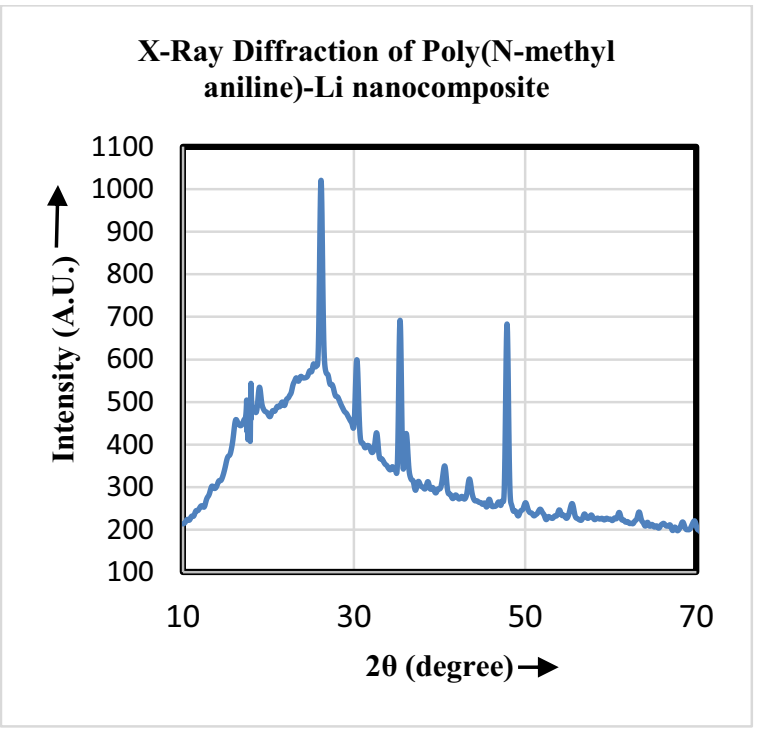

Fig.4. XRD of Poly (N- methyl aniline)-Li nanocomposite

\subsection{FE-SEM (First Emission-Scanning Electron Microscopy)}

The photograph of the Poly (N-methyl aniline)-Li nanocomposite (Figure 5) shows the morphology of the nanofibers and the polymer material as spherical shaped with agglomerated Lithium ions. The average diameter of the nanofibers (star-shaped) was in the range of $300 \pm 50 \mathrm{~nm}$ [11]. The agglomerated Lithium nanoscale materials show a spherical shape with a size of $\sim 64 \mathrm{~nm}$.
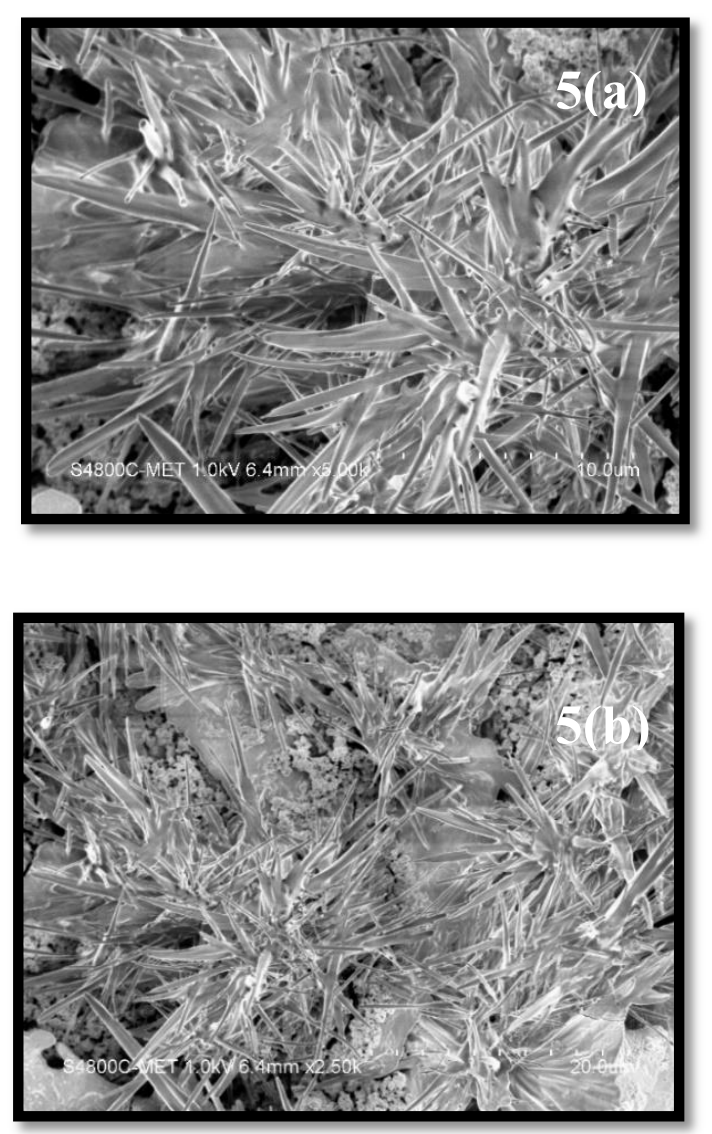

Fig.5.Poly (N- methyl aniline)-Li nanocomposite at (a) $10 \mu \mathrm{m}$ (b) $20 \mu \mathrm{m}$ : FE-SEM photograph

\section{Application as battery}

Copper coil wire and hollow aluminum pipe were employed as anode and cathode, respectively. The synthesized nanocomposite was used as an electrolyte for a battery. $2.5 \mathrm{~mL}$ of the developed electrolyte (nanocomposite) was analyzed for a single cell battery. After the connection of two cells in series, current and time measurements were carried out using measuring equipment (multimeter). After contact in parallel, the battery showed a potential of $7.08 \mathrm{~V}$, which remained the same even after 100 cycles. RC circuit diagram for charging- discharging is shown in figure 6.

The energy density of the developed battery was found according to Equation (2).

$\mathrm{E}=\int_{t 1}^{t 2} I \cdot V \cdot(t) d t(2)$ 
Where,

$\mathrm{E}=$ Energy density

$\mathrm{I}=$ Discharge current

$\mathrm{V}=$ Cell Voltage

$\mathrm{t}_{1}=$ Initial time of discharge

$\mathrm{t}_{2}=$ End time of discharge

The power density was calculated according to Equation (3).

$P=\frac{E}{(t 2-t 1)}(3)$

The power density of the prepared battery was $119.233 \mathrm{~W} / \mathrm{m}^{3}$, and was calculated using equation (2) and (3) [12].

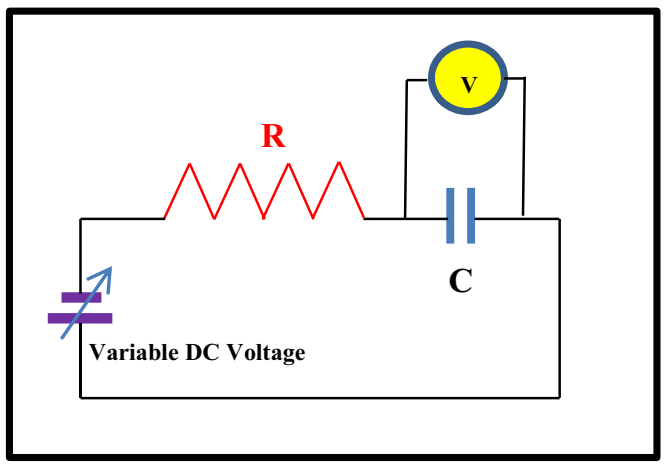

Fig.6. RC circuit for charging \& discharging of battery

Figure 8 shows the discharge tests of battery for resistances 5,10 , and $27 \mathrm{~K} \Omega$, which indicates decreasing curves pattern for the higher resistance.

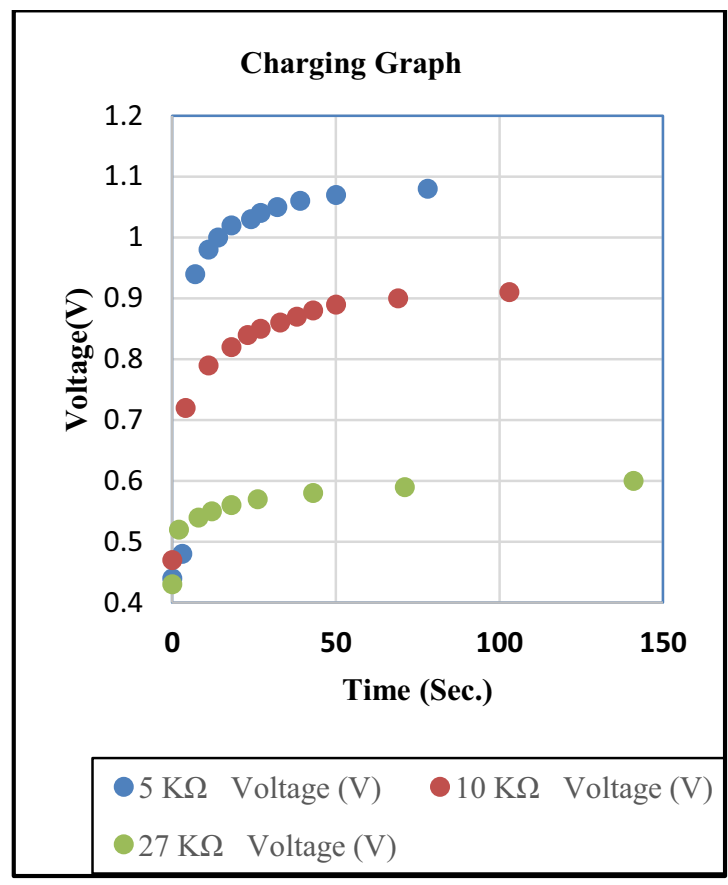

Fig.7.Charging graph of battery

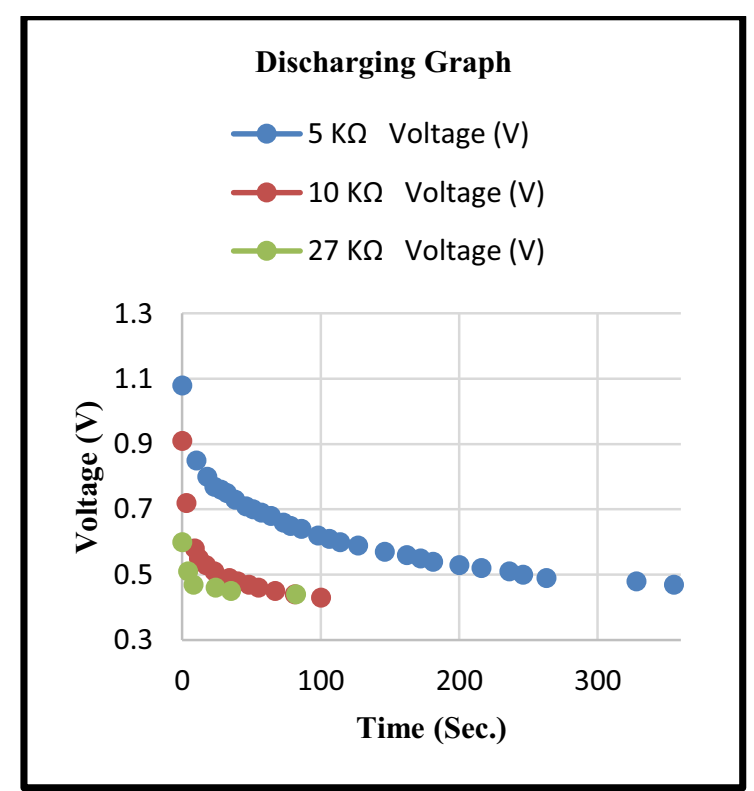

Fig.8.Discharge capacity of the battery 


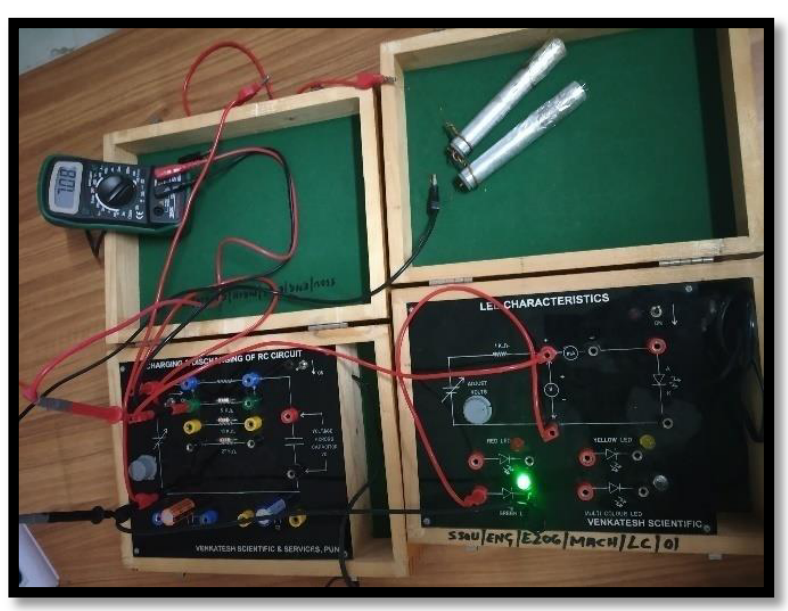

Fig.9. Photograph of (Green color)LED light glow by using battery

\section{Conclusion}

The developed nanocomposite material has given appreciable and outstanding results as an electrolyte for the battery. The networked structure of synthesized nanocomposite, with intermediate morphology of nanofibers (poly $\mathrm{N}$-methyl aniline) and spheres (Lithium), was studied using FE-SEM analysis. The power density of battery was observed to be $119.233 \mathrm{~W} / \mathrm{m}^{3}$ after 100 cycles of charging and discharging. The developed material, as an electrolyte, has shown immense potential to be a promising material for usage in batteries.

\section{References}

1. X. Han,M. Ouyang,L. Lu, J. Li,Y. ZhengZ. Li, J. power sources. 251,1 (2014)

2. L.M. Bronstein, C. Joo, R. Karlinsey, A.Ryder, J.W. Zwanziger,Chem. Mater. , 13, 10(2001)

3. E.M. Masoud, A.A. El-Bellihi, W.A. Bayoumy, M.A. Mousa, J. Alloy Compd.575 (2013)

4. N.S.Pande, DipikaJaspal, J. Ambekar, Int. J. Nanosci.16,3 (2017)

5. N.Pande, D. Jaspal, A. Malviya, A. Warke, Inorg. Nano-Met. Chem.47,7(2017)

6. N.S. Pande, DipikaJaspal, A. Warke, V.V. Chabukswar, J. polym. Res. 10,4 (2016)

7. N.S. Pande, A. Jambhale, D. Jaspal, J. Ambekar, M. Kulkarni, Inorg. Nano-Met. Chem. 24701564 (2019)

8. E.I. Iwuoha, S.E. Mavundla, V.S. Somerset, L.F. Petrik, M.J. Klink, M. Sekota, P. Bakers, Microchim.Acta.155, (2006)
9. G. Aravind, M. Raghasudha, D. Ravinder, A. Gaffoor, V. Nathanial, J. Nanostruct. Chem. 5, (2015)

10. N. Pande, D. Jaspal, J. Ambekar, V.P. Jayachandran, J. Chem. Pharm. 6 (2014)

11. B. Massoumi, N. Aalia, M. Jaymand, RSC Adv., 5 (2015)

12. A. Byeon ,A.M. Glushenkov ,B. Anasori, P. Urbankowski , J. Li , B.W. Byles, B. Blake, K.L. Van Aken, S. Kota, E. Pomerantseva, J.W. Lee , Y. Chen , Y. Gogotsi, J. Power Sources (2016) 